\title{
Energy expenditure in critically ill surgical patients. Comparative analysis of predictive equation and indirect calorimetry ${ }^{1}$
}

\author{
Gasto energético em pacientes cirúrgicos. Análise comparativa entre equação preditiva e \\ calorimetria indireta
}

\begin{abstract}
Maria Auxiliadora Martinsi, Mayra Gonçalves Menegueti" ${ }^{\mathrm{II}}$ Edson Antônio Nicolini ${ }^{\mathrm{III}}$, Michele Ferreira Picolo ${ }^{\mathrm{IV}}$, Alessandra Fabiane Lagov, Olindo Assis Martins Filhovi, Anibal Basile Filho ${ }^{\text {VII }}$

IPhD, Affiliate Professor, Intensive Care Division, Department of Surgery and Anatomy, FMRP-USP, Ribeirao Preto-SP, Brazil. Responsible for the intellectual and scientific content of the study.

IIFellow Master degree, School of Nursing of Ribeirao Preto, USP, Ribeirao Preto-SP, Brazil. Responsible for protocol design and participation in technical procedures.

IIIMD, Intensive Care Division, Department of Surgery and Anatomy, FMRP-USP, Ribeirao Preto-SP, Brazil. Responsible for data acquisition and interpretation.

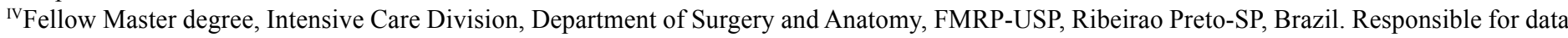
acquisition and interpretation.

vPhysiotherapist, Intensive Care Division, Department of Surgery and Anatomy, FMRP-USP, Ribeirao Preto-SP, Brazil. Responsible for data acquisition and interpretation.

${ }^{\mathrm{V}} \mathrm{PhD}$, Head of the Biomarker Research Group, Laboratory of Biomarkers, René Rachou Institute, Oswaldo Cruz Foundation, Belo Horizonte-MG, Brazil. Responsible for statistical analysis.

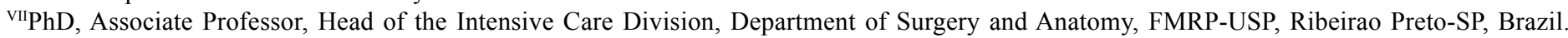
Responsible for critical revision.
\end{abstract}

\section{ABSTRACT}

PURPOSE: The aim of this investigation was to compare the resting energy expenditure (REE) calculated by the Harris-Benedict equation $\left(\mathrm{REE}_{\mathrm{HB}}\right)$ with the REE measured by indirect calorimetry $\left(\mathrm{REE}_{\mathrm{IC}}\right)$ in critically ill surgical patients under mechanical ventilation. METHODS: Thirty patients were included in this work. REE was calculated by the Harris-Benedict equation $\left(\mathrm{REE}_{\mathrm{HB}}\right) \mathrm{using}$ real body weight, and it was also measured by indirect calorimetry $\left(\mathrm{REE}_{\mathrm{IC}}\right)$, which was performed for 30 minutes.

RESULTS: $\mathrm{REE}_{\mathrm{HB}}$ had significant $(\mathrm{p}<0.0005)$ but low correlation (Spearman $\left.\mathrm{r}=0.57\right)$ with $\mathrm{REE}_{\mathrm{IC}}$, with a mean bias of $12 \mathrm{kcal}^{-1} \mathrm{~d}^{-1}$ and limits of agreement ranging from -599.7 to $623.7 \mathrm{kcal} . \mathrm{d}^{-1}$ as detected by the Bland-Altman analysis.

CONCLUSION: These findings suggest that $\mathrm{REE}_{\mathrm{IC}}$ seems to be more appropriate than $\mathrm{REE}_{\mathrm{HB}}$ for accurate measurement of REE in critically ill surgical patients under mechanical ventilation.

Key words: Calorimetry. Instrumentation. Energy Metabolism. Intensive Care.

\section{RESUMO}

OBJETIVO: O objetivo deste estudo foi comparar o gasto energético de repouso (GER), calculado pela equação de Harris-Benedict $\left(\mathrm{GER}_{\mathrm{HB}}\right)$ com o GER medido pela calorimetria indireta $\left(\mathrm{GER}_{\mathrm{CI}}\right)$ em pacientes cirúrgicos gravemente enfermos em ventilação mecânica. MÉTODOS: Trinta pacientes foram incluídos nesta investigação. O gasto energético de repouso foi calculado pela equação de Harris-Benedict $\left(\mathrm{GER}_{\mathrm{HB}}\right)$ utilizando o peso corporal real e medido pela calorimetria indireta $\left(\mathrm{GER}_{\mathrm{CI}}\right)$. A calorimetria indireta foi realizada durante 30 minutos.

RESULTADOS: O gasto energético de repouso calculado pela equação de Harris-Benedict mostrou uma correlação significativa $(\mathrm{p}<0,0005)$, porém fraca (Spearman $\mathrm{r}=0,57)$ com $\mathrm{GER}_{\mathrm{Cl}}$, com um viés médio de $12 \mathrm{kcal}^{-1} \mathrm{~d}^{-1}$ e os limites de concordância variando de - 599,7 a -623,7 kcal.d $\mathrm{d}^{-1}$ como detectados pela análise de Bland-Altman.

CONCLUSÃO: Estes achados sugerem que a calorimetria indireta parece ser mais apropriada do que a equação de Harris Benedict para a medida exata do GER em pacientes cirúrgicos gravemente enfermos em ventilação mecânica.

Descritores: Calorimetria. Instrumentação. Metabolismo Energético. Cuidados Intensivos. 


\section{Introduction}

Accurate estimation of resting energy expenditure (REE) in critically ill patients is vitally important, because it allows for adequate nutrition planning. It has been well established that both deficient and excess nutrition have a negative impact on patient outcome, especially when patients are submitted to mechanical ventilation.

Attention to the determination of energy requirements must be included among the first actions regarding care delivery to critically ill patients, since acute diseases may prompt many metabolic alterations. Traditionally, critically ill patients have elevated REE and negative nitrogen balance, which are both related to disease severity or extension of the trauma ${ }^{1,2}$. Historically, it has been observed that critically ill, febrile patients have increased protein catabolism, and this concept was the basis for offering overestimated food supply to severely ill patients via parenteral nutritional therapy in the 1970s and 1980s. Today, it is known that hypernutrition has no advantages; in fact, it poses potential risks to patients ${ }^{3}$. On the other hand, high hospital prevalence of deficient nutrition has been described, and this has been reported to occur in 30 to $50 \%$ of the patients staying in the $\mathrm{ICU}^{4}$.

Therefore, satisfactory determination of the actual energy requirements of critically ill patients must be accomplished. REE is usually determined by indirect calorimetry but, in the absence of the latter, predictive formulas such as the well-known HarrisBenedict equation ${ }^{5}$ are routinely employed for REE calculation. This equation may underestimate or overestimate REE by up to $10 \%$, depending on the patient and on the type of condition ${ }^{6}$. Many studies have found significant differences between REE values measured by indirect calorimetry and those resulting from various predictive equations ${ }^{7}$, so on the basis of the findings by Long et al. ${ }^{8}$, correction factors for attenuation of the differences between the several types of injuries diseases have often been utilized.

The aim of this study was to compare REE measured by indirect calorimetry with values predicted by the Harris-Benedict equation in critically ill surgical patients under mechanical ventilation.

\section{Methods}

This study was conducted at an ICU with nine hospital beds that assists severely ill clinical and surgical adult patients. All the postsurgical patients under mechanical ventilation and with a perspective of staying in the ICU for over 48 hours were included in this investigation, regardless of the surgery type.

This work was approved by the Ethics Committee of Hospital das Clínicas of the Faculty of Medicine of Ribeirão Preto, University of São Paulo, (Protocol 7076/2010).

Sedated, postsurgical male and female patients submitted to different types of elective and urgent surgeries and who had to undergo mechanical ventilation after volemic recovery, hemodynamic and respiratory stabilization and standard nutritional therapy of $25-30 \mathrm{kcal} \cdot \mathrm{kg}^{-1} \cdot \mathrm{d}^{-1}\left(1 \mathrm{kcal} . \mathrm{mL}^{-1}\right)$ were selected. The patients were observed between the $1^{\text {st }}$ and $5^{\text {th }}$ day of ICU stay. All the patients were stratified according to the APACHE II score upon ICU admission.

Exclusion criteria were: need for $\mathrm{FiO}_{2}$ (ratio of inhaled air) $>0.6$, mean blood pressure $<50 \mathrm{mmHg}$, HR (heart rate) $<50$ or $>140 \mathrm{bpm}$, presence of bronchopleural fistula, irreversible circulatory shock, diuresis $<50 \mathrm{~mL} . \mathrm{h}^{-1}$, brain death, and patient's refusal to participate in the study. The patients' weight was obtained by direct measurement on a portable scale (Slingscale 2002, Instrucom/Hill-Rom series, Hillembrand Industries, EUA). The patient's height, weight, sex, age, diagnosis, BMI, type of nutrition support, indirect calorimetry measurements, and REE calculated by the Harris Benedict equation were collected and tabulated.

The protocol had a mean duration of 30 minutes per patient. REE measurements were performed by indirect calorimetry $\left(\mathrm{REE}_{\mathrm{IC}}\right)$ with the aid of a metabolic cart Deltatrac Monitor (Datex-Ohmeda, Finland) connected to a mechanical ventilator (Figure 1), and the barometric and gas pressure were calibrated before each protocol. The employed techniques and apparatus have been described in detail in previous studies ${ }^{9}$. REE was also calculated by means of the Harris Benedict equation using the actual body weight $\left(\mathrm{REE}_{\mathrm{HB}}\right)$, as described below:
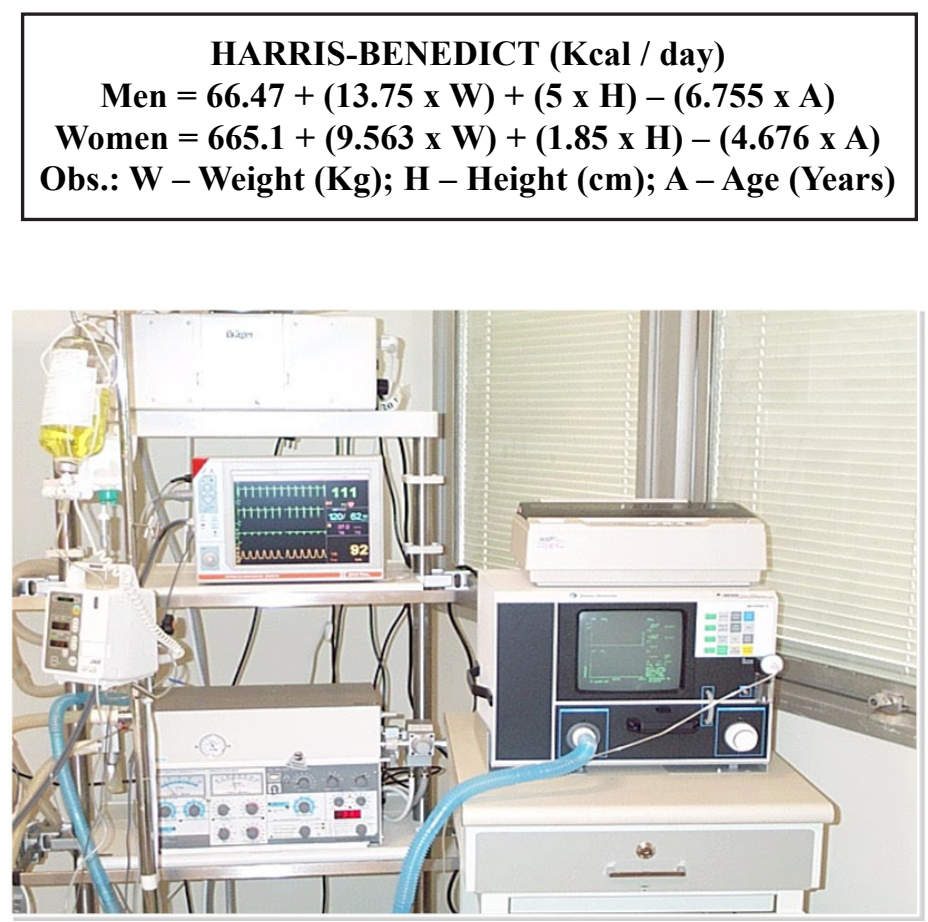

FIGURE 1 - Metabolic cart Deltatrac Monitor connected to a mechanical ventilator 


\section{Statistical analysis}

Descriptive statistics (mean and percentage) was utilized for description of the characteristics of our population. To this end, the mean values of energy expenditure of all the patients obtained by the two methods (Indirect Calorimetry and the Harris-Benedict equation) were employed for statistical analysis.

Comparative analysis of $\mathrm{REE}_{\mathrm{IC}}$ and $\mathrm{REE}_{\mathrm{HB}}$ was carried out by the non-parametric paired t test. Correlation analysis between $\mathrm{REE}_{\mathrm{IC}}$ and $\mathrm{REE}_{\mathrm{HB}}$ was done by means of the Spearman non-parametric correlation test.

Comparisons between the methods were made, in order to highlight differences between pairs of measurements performed by $\mathrm{REE}_{\mathrm{IC}}$ and predictive equations, and were further analyzed by the Bland \& Altman plot ${ }^{10}$. The GraphPad Prism Software Version 5.0.0.0 (San Diego, CA, USA) was employed for all the statistical analyses, except for the Bland \& Altman plot, which was assessed using the MedCalc ${ }^{\circledR}$ Statistical Software Version 9.6.4.0 (Mariakerke, Belgium).

\section{Results}

Thirty patients were included in this investigation (23 males and 7 females). The age varied between 16 and 80 years, with a median of $46 \pm 20$ years. The average APACHE II score obtained within the first 24 hours of admission was $23 \pm 8$ with a mean death risk of $44 \% \pm 29 \%$. The main clinical and demographic data are listed in Table 1.

The patients had undergone one of the following surgeries: laparotomy $(n=13,43.3 \%)$, victims of polytrauma submitted to orthopedic surgery $(\mathrm{n}=10,33.3 \%)$, CET victims submitted to craniotomy $(\mathrm{n}=4,13.3 \%)$, and thoracotomy $(\mathrm{n}=3$, $10 \%)$. Ten $(33.3 \%)$ of the thirty studied patients died. According to the APACHE II score, a mean number of deaths of $44 \pm 29 \%$ would be expected.

The mean REE value calculated via the Harris Benedict equation $\left(\mathrm{REE}_{\mathrm{HB}}\right)$ was $1622 \pm 257 \mathrm{kcal}^{\mathrm{d}} \mathrm{d}^{-1}$, whereas the mean REE obtained by indirect calorimetry ( $\mathrm{REE}_{\mathrm{IC}}$ ) was $1634 \pm 377 \mathrm{kcal} . \mathrm{d}^{-1}$ for the thirty patients. Despite the apparent close proximity of the mean values achieved by the two different methods employed

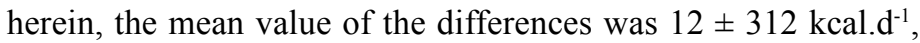
and the isolated values did not evidence any agreement between the methods. The mean values for the $\mathrm{REE}_{\mathrm{IC}}$ and $\mathrm{REE}_{\mathrm{HB}}$ measurements as well as the difference between them are detailed in Table 2 for each patient. Comparison between $\mathrm{REE}_{\mathrm{IC}}$ and $\mathrm{REE}_{\mathrm{HB}}$ using the student paired $t$ test did not give evidence of statistically significant differences $(\mathrm{p}=0.83)$; however, the differences were clinically relevant.
TABLE 1 - Clinical and demographic aspects of the studied population

\begin{tabular}{lc}
\hline Variables & Total $(\mathbf{n}=\mathbf{3 0})$ \\
\hline Age, median (range), years & $46(16-80)$ \\
Sex (M/F) & $23 / 7$ \\
Weight, median (range), kg & $75(59-125)$ \\
Height, median (range), cm & $173(157-188)$ \\
BMI, median (range), kg/m ${ }^{2}$ & $25(20-39)$ \\
APACHE II score, median (range) & $23(9-40)$ \\
Death risk, median (range) & $44 \%(5-92 \%)$ \\
Primary Surgical Procedure & $(\boldsymbol{n}, \boldsymbol{\%})$ \\
Laparotomy & $13(43.3 \%)$ \\
Orthopedic & $11(36.7 \%)$ \\
Craniotomy & $4(13.3 \%)$ \\
Thoracotomy & $2(6.7 \%)$ \\
Reason for ICU admission & $(\boldsymbol{n}, \boldsymbol{\%})$ \\
Infectious Diseases & $16(53.3 \%)$ \\
Septic Shock & $3(10 \%)$ \\
Respiratory failure & $2(6.7 \%)$ \\
Polytrauma & $6(20 \%)$ \\
Miscellaneous* & $3(10 \%)$ \\
Death (n,\%) & $10(33 \%)$ \\
\hline
\end{tabular}

*Miscellaneous: 1 each of Sd Churg-Strauss/mesenteric ischemia, perforated duodenal ulcer, and postsurgery of iliac artery bypass by aortic dissection; APACHE II = Acute Physiology and Chronic Health Evaluation II; ICU, intensive care unit; BMI, body mass index. 
TABLE 2 - Resting Energy Expenditure measured by indirect calorimetry $\left(\mathrm{REE}_{\mathrm{IC}}\right)$ and estimated by Harris-Benedict equation $\left(\mathrm{REE}_{\mathrm{HB}}\right)$, difference between $\mathrm{REE}_{\mathrm{IC}}$ and $\mathrm{REE}_{\mathrm{HB}}$ for each patient

\begin{tabular}{|c|c|c|c|}
\hline $\begin{array}{l}\text { Surgical } \\
\text { Procedure }\end{array}$ & $\begin{array}{l}\mathbf{R E E}_{\text {IC }} \\
\left(\mathrm{kcal}^{-1} \mathrm{~d}^{-1}\right)\end{array}$ & $\begin{array}{l}\mathbf{R E E}_{\mathbf{H B}} \\
\left(\mathrm{kcal}^{-1} \mathrm{~d}^{-1}\right)\end{array}$ & $\begin{array}{c}\text { Difference } \\
\left(\operatorname{REE}_{\mathrm{IC}}-\mathbf{R E E}_{\mathrm{HB}}\right)\end{array}$ \\
\hline \multicolumn{4}{|l|}{ Laparotomy } \\
\hline 1 & 1360 & 1416 & -56 \\
\hline 2 & 1440 & 1512 & -72 \\
\hline 3 & 1090 & 1530 & -440 \\
\hline 4 & 1130 & 1501 & -371 \\
\hline 5 & 1743 & 1595 & 148 \\
\hline 6 & 1459 & 1397 & 62 \\
\hline 7 & 1349 & 1624 & -275 \\
\hline 8 & 2190 & 2025 & 165 \\
\hline 9 & 1830 & 1716 & 114 \\
\hline 10 & 1155 & 1530 & -375 \\
\hline 11 & 2258 & 1576 & 682 \\
\hline 12 & 1458 & 1276 & 182 \\
\hline 13 & 1643 & 1266 & 377 \\
\hline \multicolumn{4}{|l|}{ Orthopedic } \\
\hline 1 & 1940 & 1917 & 23 \\
\hline 2 & 1203 & 1507 & -304 \\
\hline 3 & 960 & 1226 & -266 \\
\hline 4 & 1280 & 1645 & -365 \\
\hline 5 & 2116 & 1508 & 608 \\
\hline 6 & 1913 & 1733 & 180 \\
\hline 7 & 2089 & 1744 & 345 \\
\hline 8 & 1678 & 1722 & -44 \\
\hline 9 & 1988 & 1700 & 288 \\
\hline 10 & 2050 & 1501 & 549 \\
\hline 11 & 1958 & 1730 & 228 \\
\hline \multicolumn{4}{|l|}{ Craniotomy } \\
\hline 1 & 1468 & 1547 & -79 \\
\hline 2 & 1774 & 2104 & -330 \\
\hline 3 & 1419 & 1664 & -245 \\
\hline 4 & 1363 & 1637 & -274 \\
\hline \multicolumn{4}{|l|}{ Thoracotomy } \\
\hline 1 & 1470 & 1351 & 119 \\
\hline 2 & 2247 & 2462 & -215 \\
\hline Mean \pm SD & $1634 \pm 378$ & $1622 \pm 257$ & $12 \pm 312$ \\
\hline
\end{tabular}

Analysis of the correlation between the measurements demonstrated that $\mathrm{REE}_{\mathrm{HB}}$ had significant $(\mathrm{p}<0.0005)$ but low correlation (Spearman $\mathrm{r}=0.57$ ) with $\mathrm{REE}_{\mathrm{IC}}($ Figure 2$)$.

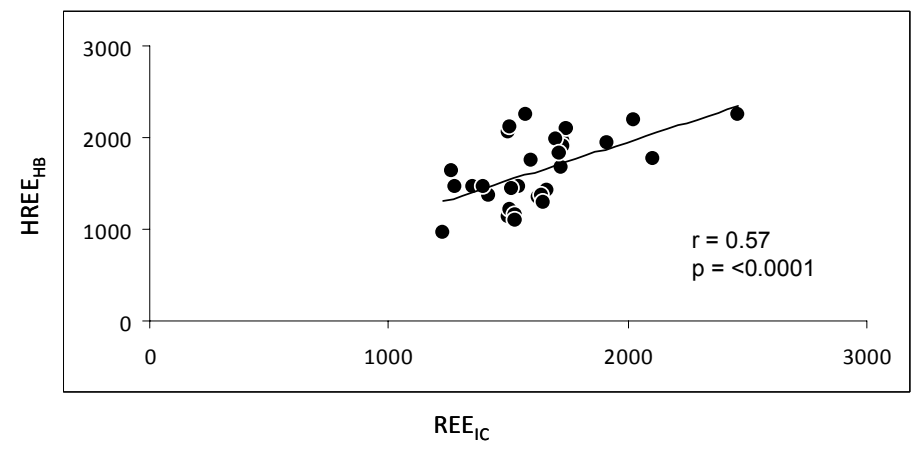

FIGURE 2 - Spearman correlation analysis showing a positive but low correlation $(r=0.57)$ between REE determined by the Harris Benedict equation $\left(\mathrm{REE}_{\mathrm{HB}}\right)$ and that obtained by indirect calorimetry $\left(\mathrm{REE}_{\mathrm{IC}}\right)$

This correlation is positive, but it does not reflect on an agreement between the values achieved by the two different methods. Many authors use correlations in order to compare variables obtained by means of two distinct methods. In the present case, employing a correlation is inadequate. Moreover, it is necessary to employ a method that assesses agreement between the methods. To address this issue, we decided to use the method of Bland and Altman to evaluate whether there was agreement. Our results showed that $\mathrm{REE}_{\mathrm{HB}}$ has low agreement with $\mathrm{REE}_{\mathrm{IC}}$, with a mean bias of $12 \mathrm{kcal} \cdot \mathrm{d}^{-1}$, and that the limits of agreement ranged from - 599.7 to $623.7 \mathrm{kcal. \textrm {d } ^ { - 1 }}$, as seen in Figure 3 .

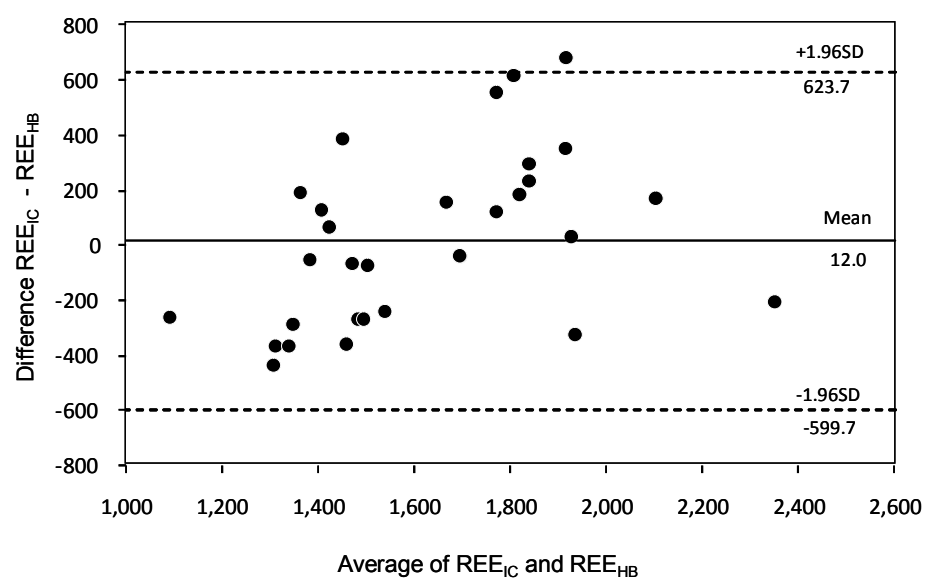

FIGURE 3 - Comparative analysis of resting energy expenditure determined by the Harris Benedict equation $\left(\mathrm{REE}_{\mathrm{HB}}\right)$ with that determined by indirect calorimetry $\left(\mathrm{REE}_{\mathrm{IC}}\right)$ 


\section{Discussion}

The aim of this study was to compare the REE values obtained for critically ill patients under mechanical ventilation by means of the Harris-Benedict equation with those achieved by indirect calorimetry.

REE is routinely measured via predictive equations in critically ill patients. However, this practice has long been questioned by various authors because this methodology under- or overestimates the actual energy requirements of each patient by up to $50 \%$. Indeed, recent studies have pointed out that no predictive equation has been able to accurately predict REE in hospitalized patients ${ }^{11}$. Due to the lability and physiological instability of these individuals, it is reasonable to suppose that the critically ill patient presents an array of nuances that compromise application of predictive equations. Among such subtleties are sedation and/or neuromuscular blocking drugs, vasoactive catecholamines, hemodynamic instability, nutritional therapy (thermogenic effect), and bacteremia and body temperature events (hypo- or hyperthermia), which all account for inaccurate REE predictions even when indirect calorimetry is employed. In other words, it is difficult to reach a steady state in critically ill patients, so repeated and constant measurements as a function of time are hardly ever obtained. Interestingly, in the present study a constant respiratory quotient (RQ) value was detected throughout the entire protocol, which reflects attainment of a steady state for all our patients.

However, it is noteworthy that inadequate nutrient supply may be offered to patients when these predictive equations are utilized. This culminates in under- or overnutrition, whose deleterious effects have been well-documented ${ }^{12}$. Indirect calorimetry allows for observation of the variability of the daily REE, enabling the hospital staff to make the necessary corrections, so that energy balance is maintained during the hospital stay.

Given the above considerations, which would be the consequences of under- or overnutrition for postsurgical critical patients?

It is known that the delivery of insufficient energy supply to severely ill patients is characterized by lean muscle mass loss and significant nitrogen elimination via the urine, which leads to rapid deterioration of the patient's health status and undernutrition. Under these circumstances, the effects of undernutrition are associated with reduced strength of the musculature involved in respiration, which poses difficulties to the process of weaning patients off mechanical ventilation. Moreover, predisposition to infections is increased, thereby elevating morbi-mortality. On the other hand, excess administration of nutrients causes additional stress, which culminates in cardiopulmonary (hypercapnea and difficulties in weaning patients off mechanical ventilation), liver and metabolic complications ${ }^{13}$.

So what is the role played by indirect calorimetry when it comes to individualization of nutrient offer to critically ill patients? Can the use of calorimetry prevent errors with respect to nutrient supply?
Despite the large number of works on this issue, few wellcontrolled studies have been conducted to solve these queries. Vo et al. ${ }^{3}$ have analyzed the impact of the infusion of high parenteral glucose concentrations on the mortality during the first 24 postsurgical hours. These authors observed the behavior of the RQ of two groups of patients, namely one that received 1.5 -fold REE $(R Q>0.95)$ and another that was administered the equivalent to the REE $(\mathrm{RQ}<0.95)$. There was a larger number of septic events and higher mortality in the group that received more carbohydrates, as compared to the group that received nutrients only to meet REE requirements. In another clinical study involving burnt patients, the authors came to the conclusion that a high-calorie diet increases $\mathrm{VCO}_{2}$, as opposed to the formulation containing only a high percentage of carbohydrates ${ }^{14}$. Both under- and overnutrition may be harmful to postsurgical patients. The current consensus is that the offered REE should be the same as the measured REE.

Another relevant aspect concerns the occurrence of a complicated postsurgical period, which may take place with respiratory system complications such as the acute respiratory distress syndrome (ARDS). This condition accentuates the initial undernutrition status as well as nitrogen loss via the urine. The hypermetabolism detected in these patients elevates the carbon dioxide production $\left(\mathrm{VCO}_{2}\right)$, aggravating a pre-existing condition of $\mathrm{CO}_{2}$ removal ${ }^{15}$. Besides the hypermetabolism in critically ill patients with ARDS, there are intra-individual daily variations in REE. Thus, the aim of nutritional therapy is twofold: to avoid hypernutrition and prevent severe undernutrition, which may cause muscular fatigue and compromise patient's weaning from mechanical ventilation.

Although indirect calorimetry remains as the gold standard for REE measurement, this methodology requires expensive equipment and technical expertise. Moreover, indirect calorimetry poses some problems in specific clinical situations, such as patients ventilated with inspired oxygen concentration $\left(\mathrm{FiO}_{2}>0.6\right)$, along with environmental variables, including room temperature, barometric pressure, and humidity, which can all affect the calorimeter data. Furthermore, data collection may be timeconsuming and requires trained staff. A potential limitation of the present investigation is the fact that the study was restricted to critically ill surgical patients. Therefore, our results should not be generalized to other groups of critically ill patients.

\section{Conclusion}

Our findings indicate that although the resting energy expenditure calculated by the Harris Benedict equation using the portable scale measurement led to good correlation with indirect calorimetry, the low correlation index (0.57) and the wide range of variability suggest that indirect calorimetry still is more appropriate for the accurate measurement of REE in critically ill surgical patients under mechanical ventilation as compared to predictive equations. Further studies aiming to validate these findings in a blind analysis are underway. 


\section{References}

1. Hwang TL, Huang SL, Chen MF. The use of indirect calorimetry in critically ill patients. The relationship of measured energy expenditure to injury severity score, septic severity score, and APACHE II score. J Trauma. 1993;34:247-51.

2. Frankenfield DC, Wiles CE, Bagley S, Siegel JH. Relationships between resting and total energy expenditure in injured and septic patients. Crit Care Med. 1994;22:1796-804.

3. Vo NM, Waycaster M, Acuff RV, Lefemine AA. Effects of postoperative carbohydrate overfeeding. Am Surg. 1987;53:632-5.

4. Border JR, Hassett J, LaDuca J, Seibel R, Steinberg S, Mills B, Losi P, Border D. The gut origin septic states in blunt multiple trauma (ISS $=40$ ) in the ICU. Ann Surg. 1987;206:427-48.

5. Harris JA, Benedict FG. A biometric study on basal metabolism in men. Washington DC: Carnegie Institute of Washington; 1919.

6. Daly JM, Heymsfield SB, Head CA, Harvey LP, Nixon DW, Katzeff $\mathrm{H}$, Grossman GD. Human energy requirements: overestimation by widely used prediction equation. Am J Clin Nutr. 1985;42:1170-4.

7. Pirat A, Tucker AM, Taylor KA, Jinnah R, Finch CG, Canada TD, Nates JL. Comparison of measured versus predicted energy requirements in critically ill cancer patients. Respir Care. 2009;54:487-94.
8. Long CL, Schaffel N, Geiger JW, Schiller WR, Blakemore WS. Metabolic response to injury and illness: estimation of energy and protein needs from indirect calorimetry and nitrogen balance. J Parenter Enteral Nutr. 1979;3:452-6.

9. Auxiliadora-Martins M, Coletto FA, Campos AD, Basile-Filho A. Indirect calorimetry can be used to measure cardiac output in septic patients? Acta Cir Bras. 2008;23:118-25.

10. Bland JM, Altman DG. Measuring agreement in method comparison studies. Stat Methods Med Res. 1999;8:135-60.

11. Boullata J, Williams J, Cottrell F, Hudson L, Compher C. Accurate determination of energy needs in hospitalized patients. J Am Diet Assoc. 2007;107:393-401.

12. Kemper M, Weissman C, Hyman AI. Caloric requirements and supply in critically ill surgical patients. Crit Care Med. 1992;20:344-8.

13. Saffle JR, Larson CM, Sullivan J. A randomized trial of indirect calorimetry-based feedings in thermal injury. J Trauma. 1990;30:776-82.

14. Talpers SS, Romberger DJ, Bunce SB, Pingleton SK. Nutritionally associated increased carbon dioxide production. Excess total calories versus high proportion of carbohydrate calories. Chest. 1992;102:551-5. 15. Frankenfield DC, Alam S, Bekteshi E, Vender RL. Predicting dead space ventilation in critically ill patients using clinically available data. Crit Care Med. 2010;38:288-91.

\section{Correspondence:}

Maria Auxiliadora Martins

Hospital das Clínicas da Faculdade de Medicina de Ribeirão Preto - USP

Departamento de Cirurgia e Anatomia

Divisão de Terapia Intensiva

Av. Bandeirantes, 3900

14049-900 Ribeirão Preto - SP Brasil

Tel./Fax: (55 16)3602-2439

mamartins@hcrp.usp.br

mam_martins@hotmail.com

Conflict of interest: none

Financial source: none

${ }^{1}$ Research performed at Intensive Care Division, Department of Surgery and Anatomy, Faculty of Medicine of Ribeirao Preto, University of Sao Paulo (FMRP-USP), Ribeirao Preto-SP, Brazil.

Presented at the XII National Congress on Experimental Surgery of the Brazilian Society for Development of Research in Surgery-SOBRADPEC, 2011 October 26-29 Ribeirao Preto-SP, Brazil. 